\title{
Progressive fibrosing interstitial lung disease associated with systemic autoimmune diseases
}

\author{
Aryeh Fischer $^{1}$ (D) Jörg Distler ${ }^{2}$ (D)
}

Received: 26 March 2019 / Revised: 12 July 2019 / Accepted: 30 July 2019/Published online: 19 August 2019

(C) The Author(s) 2019

\begin{abstract}
Interstitial lung disease (ILD) is a common manifestation of systemic autoimmune diseases and a leading cause of death in these patients. A proportion of patients with autoimmune ILDs develop a progressive fibrosing form of ILD, characterized by increasing fibrosis on high-resolution computed tomography, worsening of lung function, and early mortality. Autoimmune disease-related ILDs have a variable clinical course and not all patients will require treatment, but all patients should be monitored for signs of progression. Apart from systemic sclerosis-associated ILD, the limited evidence to support the efficacy of immunosuppression as a treatment for ILDs is based mainly on small retrospective series and expert opinion. Non-clinical data suggest that there are commonalities in the mechanisms that drive progressive fibrosis in ILDs with an immunological trigger as in other forms of progressive fibrosing ILD. This suggests that nintedanib and pirfenidone, drugs known to slow disease progression in patients with idiopathic pulmonary fibrosis, may also slow the progression of ILD associated with systemic autoimmune diseases. In the SENSCIS $®$ trial, nintedanib reduced the rate of ILD progression in patients with systemic sclerosis-associated ILD. The results of other large clinical trials will provide further insights into the role of anti-fibrotic therapies in the treatment of autoimmune disease-related ILDs.
\end{abstract}

Keywords Connective tissue diseases $\cdot$ Mortality $\cdot$ Pulmonary fibrosis $\cdot$ Rheumatic diseases $\cdot$ Systemic sclerosis

\section{Introduction}

Interstitial lung disease (ILD) is a common manifestation of systemic autoimmune diseases (also referred to as connective tissue diseases) including systemic sclerosis (SSc) [1], rheumatoid arthritis (RA) [2], mixed connective tissue disease (MCTD) [3], polymyositis/dermatomyositis [4], and Sjögren's syndrome [5]. The reported prevalence of ILD in patients with systemic autoimmune disease varies widely depending on the methodology used and the population studied. A proportion of patients with systemic autoimmune diseases develop a progressive fibrosing form of ILD, characterized by increasing fibrosis on high-resolution computed tomography

Aryeh Fischer

aryeh.fischer@ucdenver.edu

1 University of Colorado School of Medicine, 1635 Aurora Court, Denver, CO 80045, USA

2 University of Erlangen-Nuremberg, Krankenhausstrasse 12, 91054 Erlangen, Germany
(HRCT), worsening of lung function, and early mortality [6-8]. The proportion of patients with autoimmune ILDs who develop progressive fibrosis is not known, but in an online survey, rheumatologists and pulmonologists with experience in managing patients with ILDs estimated it to be 24 $31 \%$ of patients [9]. Combining information from this survey with a systematic review of published literature, it was estimated that $13-40 \%$ of patients with autoimmune ILDs develop a progressive fibrosing phenotype [10].

In this article, we will describe the impact of ILD in patients with systemic autoimmune diseases, the current management of autoimmune ILDs, and the potential role of anti-fibrotic therapy in the treatment of autoimmune ILDs with a progressive fibrosing phenotype.

\section{ILDs in autoimmune diseases}

Systemic autoimmune diseases are associated with a range of pulmonary manifestations including pleural disease (pleuritis, pleural effusion, and pleural thickening), airways disease, pulmonary hypertension, vasculitis, diffuse alveolar hemorrhage, 
and ILD [11]. ILD often appears early in the course of systemic autoimmune disease and may even be the first manifestation of the disorder [11-13]. In addition, there exists a group of patients with interstitial pneumonia who show some features of autoimmunity but do not meet diagnostic criteria for any recognized autoimmune disease $[14,15]$.

ILD is particularly common in patients with SSc; indeed, ILD (defined as pulmonary fibrosis seen on HRCT or chest radiography, most pronounced in the basilar portions of the lungs, or the occurrence of idiopathic "Velcro" crackles on auscultation) is included in the classification criteria for SSc [16]. In the Canadian Scleroderma Research Group registry, ILD was evident on HRCT in $64 \%$ of patients who had HRCT scans available, while $26 \%$ of patients had ILD according to the presence of basilar "Velcro" crackles on auscultation and $22 \%$ had ILD based on chest X-ray [1]. In a recent analysis of data from 21 referral centers in Spain, $43 \%$ of 1374 patients with SSc had evidence of pulmonary fibrosis on chest radiograph or HRCT [17]. ILD is a rarer occurrence in patients with RA, but still affects a large number of patients. The prevalence of ILD in patients with RA varies across studies due to differences in the populations studied and the criteria used to define ILD. In an analysis of data from 150 consecutive outpatients with RA (irrespective of signs/symptoms of ILD) at a single UK center, 28 (6.2\%) had ILD on HRCT [18], while a multicenter study of 1460 patients with early RA $(<2$ years of symptoms) found that 52 patients (3.6\%) had ILD at baseline or developed it within 3 years of follow-up [19]. In a retrospective analysis of medical records from 582 patients with RA, the lifetime risk of developing ILD was estimated to be $7.7 \%$, compared with $0.9 \%$ in a matched cohort without RA [2]. Patients with more active RA, measured using Disease Activity Score using 28 joints (DAS28) or based on markers of disease activity such as erythrocyte sedimentation rate, appear to be at increased risk of developing ILD [2, 19, 20]. A prospective analysis of 1419 patients with RA at a US center found that patients with high or moderate disease activity defined by DAS28 had a 2-fold increased risk of developing ILD compared with those in remission or with low disease activity over a mean follow-up of 5.6 years. For every unit increase in the DAS28, the risk of ILD increased by 35\% [20].

Radiological and histopathological patterns are observed at varying frequencies across different forms of autoimmune disease-associated ILD. In SSc-ILD, the typical pattern on HRCT or histology is non-specific interstitial pneumonia (NSIP) pattern, although a usual interstitial pneumonia (UIP) pattern may also be observed $[21,22]$. NSIP is also the predominant pattern on HRCT or biopsy in patients with ILD associated with Sjögren's syndrome or polymyositis/ dermatomyositis [23-25]. In contrast, the most common pattern seen on HRCT or lung biopsy in patients with RA-ILD is UIP $[2,13,26]$. In an analysis of 230 patients with RA-ILD in the BRILL network in the UK, $65 \%$ of patients had UIP on
HRCT while $24 \%$ had NSIP [26]. It is important to note that patterns evident on HRCT are not fixed but may evolve over time; for example, patients who have a largely non-fibrotic pattern on HRCT at the time of diagnosis may later develop a more fibrotic form of the disease [27].

The symptoms of cough, dyspnea, and fatigue associated with ILD can contribute to the impairment of quality of life in patients with systemic autoimmune diseases. A survey of 50 patients with RA-ILD at a US center found that the severity of fatigue and dyspnea were the strongest predictors of physical health impairment, while the severity of cough, fatigue, and dyspnea were the strongest predictors of mental health impairment [28]. Dyspnea has been reported by patients with SSc as one of the main factors driving their functional disability [29].

\section{Progression of fibrosing ILDs}

Progression of autoimmune ILDs is characterized by deterioration in lung function, which may be assessed through measurement of forced vital capacity (FVC) (lung volume) and diffusion capacity of the lungs for carbon monoxide (DLco) (the lungs' capacity for gas exchange) [30]. Lung function may decline rapidly after ILD is diagnosed. In a study of 695 patients with SSc in the European Scleroderma Trials and Research (EUSTAR) cohort, approximately one-third of patients had DLco $<50 \%$ predicted within 3 years of the onset of Raynaud's phenomenon [31]. In an analysis of 167 patients with RA-ILD referred to a tertiary care center, the proportion of patients with $\mathrm{FVC}<50 \%$ predicted increased from $14 \%$ at diagnosis to $22 \%$ after 5 years, while the proportion of patients with DLco $<40 \%$ predicted increased from $29 \%$ at diagnosis to $40 \%$ after 5 years; patients with a UIP pattern on HRCT were more likely to progress to DLco $<40 \%$ predicted than those with NSIP [8]. The course of ILD progression in patients with other autoimmune diseases is not well documented, but it is clear that ILD progresses in a significant proportion of patients with these diseases. Among 107 patients with ILD associated with polymyositis/dermatomyositis treated with immunosuppressants, $16 \%$ had a decline in FVC of $\geq 10 \%$ predicted and/or a decline in DLco of $\geq 15 \%$ predicted over a median follow-up of 34 months [32]. In an analysis of 18 patients with Sjögren's syndrome and ILD followed for a median of 38 months, 5 (28\%) had a decline in FVC of $\geq 10 \%$ predicted or a decline in DLco of $\geq 15 \%$ predicted despite immunosuppression [33]. In an analysis of 75 patients with anti-synthetase syndrome-ILD receiving anti-inflammatory therapy, 6 patients $(8.0 \%)$ had a decline in $\mathrm{FVC}$ of $>10 \%$ predicted and/or a decline in DLco of $>15 \%$ predicted 1 year after diagnosis of ILD. Of 36 patients who had an increase in FVC of $>10 \%$ predicted and/or increase in DLco of $>15 \%$ predicted after 1 year, $12(33 \%)$ had a deterioration over the following 2 years [34]. 
ILD is a major cause of death in patients with systemic autoimmune diseases. In an analysis of 1072 deaths in patients with SSc in the EUSTAR database, ILD was listed as the cause of death in $16.8 \%$ of cases, followed by pulmonary arterial hypertension (14.7\%) and cancer (13.1\%) (Fig. 1) [35]. A greater extent of fibrosis on HRCT and decline in FVC or DLco are established predictors of mortality in patients with SSc-ILD [7, 36-38]. A seminal study found that patients with extensive disease, defined as $>30 \%$ extent of fibrosis on HRCT, or 10-30\% extent of fibrosis on HRCT plus FVC $<70 \%$ predicted, had much greater mortality than patients with more limited disease (HR 3.46) [36]. The presence of ILD also markedly increases mortality in patients with RA [2, 39, 40]. Among 679 patients in a Danish registry, oneyear mortality in patients with RA-ILD was $14 \%$, compared with $4 \%$ in RA patients without ILD who were matched for age, gender, and time since diagnosis of RA (Fig. 2) [40]. Tenyear mortality in these groups was $60 \%$ and $35 \%$, respectively [40]. Predictors of mortality in patients with RA-ILD include the presence of a UIP pattern on HRCT (Fig. 3), a greater extent of fibrosis on HRCT, and lower FVC or DLco [26, 41-44]. In an analysis of 137 patients with RA-ILD at a single US center, a baseline FVC below the mean of the cohort (68.7\% predicted) and a decline from baseline in FVC $\geq$ $10 \%$ predicted at any time over the follow-up period (median 4.8 years) were predictors of mortality (HRs 1.46 and 2.57, respectively) after controlling for age, sex, smoking, and HRCT pattern [41]. A greater extent of fibrosis on HRCT has also been associated with worse survival in patients with MCTD [3].

\section{Treatment of autoimmune ILDs}

Not all patients with autoimmune disease-related ILD require treatment. Pharmacotherapy with immunosuppression is generally reserved for patients with clinically significant, progressive disease $[45,46]$, while those with non-progressive ILD may remain untreated but should be monitored closely for signs of progression. There is no agreed definition of disease progression in ILD, but in practice, assessment of disease progression is likely to be based on clinicians' assessment of symptoms, pulmonary function tests, and/or imaging. With this in mind, and considering the other manifestations of the disease that need to be considered when managing patients with autoimmune diseases, cross-disciplinary collaboration between pulmonologists and rheumatologists is key to identifying patients with autoimmune disease-ILD who require treatment and deciding on the therapy that should be given [47].

Immunosuppressants are the standard of care for systemic autoimmune diseases and may be effective in slowing the progression of ILD in some patients. However, other than in SSc-ILD, there is no evidence from randomized double-blind trials to support the efficacy of immunosuppressants in treating ILD. In the absence of a robust evidence base to inform therapeutic decision-making, the choice of therapy for autoimmune ILD is based on clinical experience rather than data.

Data from randomized controlled trials support the use of cyclophosphamide (CYC) and mycophenolate mofetil (MMF) to treat SSc-ILD. In the Fibrosing Alveolitis in Scleroderma Trial (FAST), subjects were randomized to receive low-dose prednisolone plus CYC for 6 months followed by oral azathioprine for 6 months, or placebo for 1 year. At the end of the treatment period, there was an improvement of $2.4 \%$ in FVC \% predicted with active treatment versus a decline of $3.0 \%$ with placebo [48]. In Scleroderma Lung Study I (SLS I), among 145 patients with SSc who completed 6 months of treatment, the mean decline from baseline in FVC \% predicted at 1 year was $1.0 \%$ in patients treated with CYC versus $2.6 \%$ in those treated with placebo [49]. Based on the results of these trials, guidelines for the treatment of SScILD issued by the European League Against Rheumatism Collaborative Initiative (EULAR) recommend the use of tailored CYC therapy, in particular for patients with progressive
Fig. 1 Causes of death in patients with SSc in the European Scleroderma Trials and Research (EUSTAR) cohort. Adapted from [35]. Republished with permission of Ann Rheum Dis, from Mapping and predicting mortality from systemic sclerosis, Elhai et al., 76(11), 2017; permission conveyed through Copyright Clearance Center, Inc.

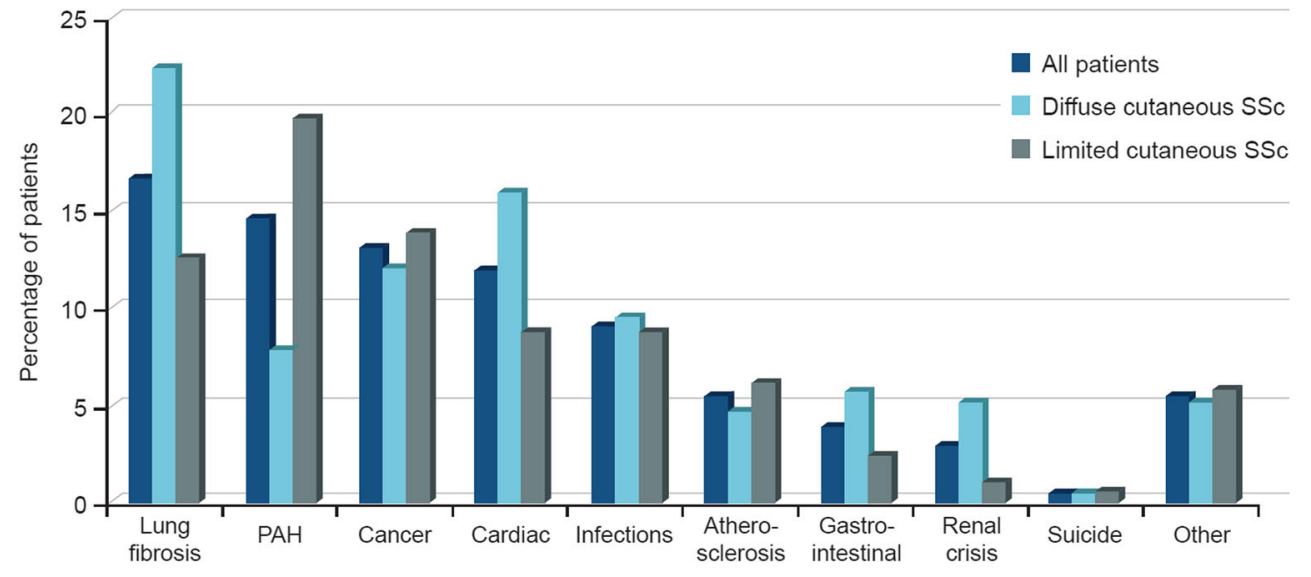


Fig. 2 Kaplan-Meier estimate of mortality in patients with RA-ILD compared with patients with RA without ILD (matched by age, sex, and time since diagnosis of RA). Adapted from [40]. Republished with permission of Ann Rheum Dis, from A population-based cohort study of rheumatoid arthritis-associated interstitial lung disease: comorbidity and mortality, Hyldgaard C et al., 76(10), 2017; permission conveyed through Copyright Clearance Center, Inc.

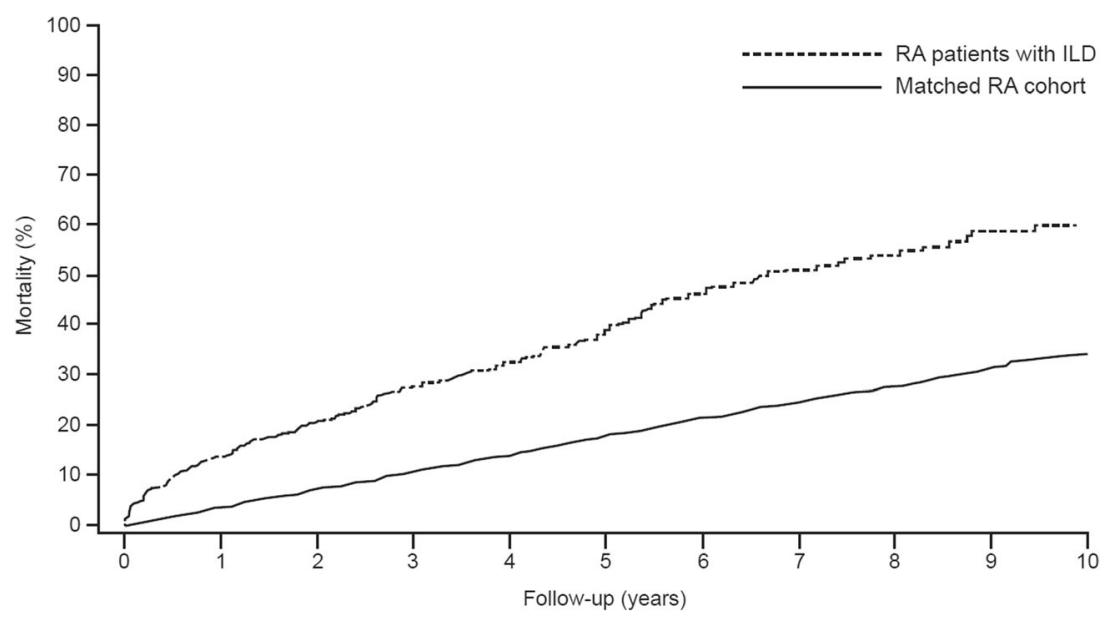

disease [50, 51]. However, the toxicity of CYC limits it to short-term use. The latest EULAR guidelines did not consider the findings of SLS II, which showed that treatment with oral MMF for 2 years resulted in the same improvement in FVC as oral CYC for 1 year followed by placebo for 1 year (absolute changes of $2.19 \%$ and $2.88 \%$ predicted, respectively), with better tolerability [52]. However, MMF is now the most widely used therapy for SSc-ILD and has been endorsed as firstline therapy by consensus panels of experts [46, 53, 54]. Rituximab and azathioprine are also used in the treatment of SSc-ILD, but the evidence that these drugs may preserve or improve lung function in these patients comes solely from retrospective or open-label studies [55-58].

Beyond SSc-ILD, more robust trial data are needed to determine the role of immunosuppressant therapy for autoimmune-associated ILDs. Although CYC, MMF, rituximab, and azathioprine are also commonly used in the treatment of RA-ILD, the evidence to support their use comes solely from retrospective or observational studies [59-62]. In a retrospective analysis of 206 patients with RA-ILD in the
BRILL network, 21 had received pulsed CYC for progressive ILD; survival time was 72 months in patients treated with CYC compared with 43 months in patients with better baseline lung function who did not receive CYC [61]. In an observational study at a single UK center, lung function changes were assessed in 44 patients with RA-ILD treated with rituximab between 2004 and 2015 (total follow-up 195 patientyears) [62]. The median relative change in FVC was $1.2 \%$ predicted in the 6-12 months after initiation of rituximab compared with a decline of $2.4 \%$ predicted in the $6-12$ months before treatment [62]. At the latest time point with evaluable data, 30 patients $(68 \%)$ did not meet the criteria for ILD progression (i.e., did not have a decline in FVC of $>10 \%$ predicted or DLco of $>15 \%$ predicted, worsening of ILD score on HRCT, or death from progressive lung disease) [62]. In an uncontrolled open-label Spanish registry, of 63 patients with RA-ILD treated with abatacept for 12 months, FVC \% predicted remained stable in approximately two-thirds of patients and improved by $\geq 10 \%$ from baseline in approximately onefifth of patients [63]. A number of other retrospective/
Fig. 3 Kaplan-Meier estimate of survival in patients with RA-ILD and UIP or NSIP patterns on HRCT. Adapted from [41]. Reproduced with permission of the (C) ERS 2019. European Respiratory Journal Feb 2016, 47 (2) 588-596; DOI: https://doi.org/ 10.1183/13993003.00357-2015.

This material has not been reviewed prior to release; therefore, the European Respiratory Society may not be responsible for any errors, omissions or inaccuracies, or for any consequences arising therefrom, in the content

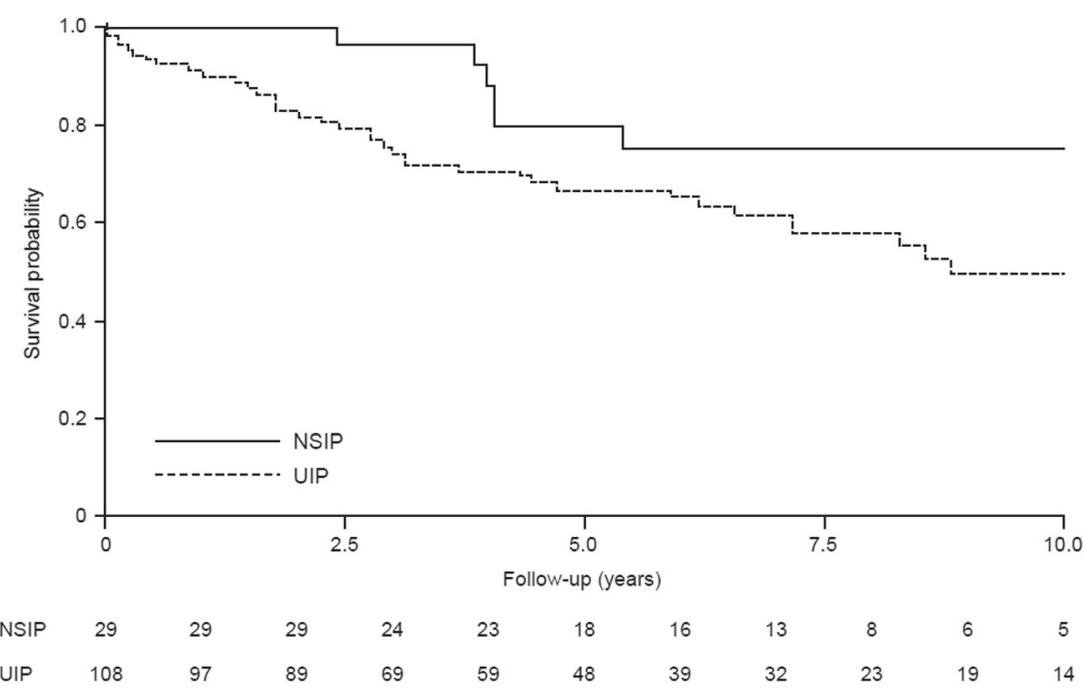


observational studies have shown preservation or improvement in lung function in patients with other autoimmune ILDs treated with immunosuppressants including polymyositis/dermatomyositis $[59,64]$ and anti-synthetase syndrome [65, 66]; however, these studies were uncontrolled and lung function was measured over limited time periods ( 1 to 4 years).

There is some evidence linking the use of DMARDs such as methotrexate to the development or worsening of ILD in rare cases [67], but a causal relationship has not been established. In a retrospective analysis of 78 patients with RA-ILD at a Mexican referral center, patients taking methotrexate prescribed to treat ILD had better survival compared with those not receiving methotrexate [68].

\section{Potential role of anti-fibrotic therapy in fibrosing autoimmune ILDs with a progressive phenotype}

Research is ongoing into whether the addition of antifibrotic therapies that have been shown to slow the progression of lung fibrosis in patients with IPF might be added to immunosuppressant therapy to slow the progression of fibrosing ILD in patients with systemic autoimmune diseases. Non-clinical studies suggest that there are commonalities in the mechanisms that drive progressive fibrosis between ILDs associated with immunological diseases and ILDs with other causes [69-72]. Progressive fibrosing ILDs are believed to be triggered by repetitive

Table 1 Ongoing and recently completed trials in patients with ILDs related to systemic autoimmune diseases

\begin{tabular}{|c|c|c|c|c|}
\hline $\begin{array}{l}\text { Trial name (ClinicalTrials.gov } \\
\text { identifier) }\end{array}$ & Patient population & $\begin{array}{l}\text { Sample } \\
\text { size }\end{array}$ & Treatment groups & Primary endpoint \\
\hline SENSCIS® (NCT02597933) [94] & SSc-ILD & 580 & $\begin{array}{l}\text { Nintedanib versus } \\
\text { placebo }^{a}\end{array}$ & $\begin{array}{l}\text { Rate of decline in FVC over } \\
52 \text { weeks (mL/year) }\end{array}$ \\
\hline INBUILD® (NCT02999178) [96] & $\begin{array}{l}\text { Progressive fibrosing ILDs other than } \\
\text { IPF }\end{array}$ & 663 & $\begin{array}{l}\text { Nintedanib versus } \\
\text { placebo }^{\text {b }}\end{array}$ & $\begin{array}{l}\text { Rate of decline in FVC over } \\
52 \text { weeks (mL/year) }\end{array}$ \\
\hline TRAIL1 (NCT02808871) & RA-ILD & 270 & $\begin{array}{l}\text { Pirfenidone versus } \\
\text { placebo }^{c}\end{array}$ & $\begin{array}{l}\text { Proportion of patients with a } \\
\text { decline in } \mathrm{FVC} \geq 10 \% \\
\text { predicted or death at week } 52\end{array}$ \\
\hline SLS III (NCT03221257) & SSc-ILD & 150 & $\begin{array}{l}\text { Pirfenidone added to } \\
\text { MMF } \\
\text { versus MMF alone }^{\mathrm{d}}\end{array}$ & $\begin{array}{l}\text { Change in FVC \% predicted at } \\
\text { month } 18\end{array}$ \\
\hline NCT03856853 & SSc-ILD & 144 & $\begin{array}{l}\text { Pirfenidone versus } \\
\text { placebo }^{\text {e }}\end{array}$ & $\begin{array}{l}\text { Change in FVC } \% \text { predicted at } \\
\text { week } 52\end{array}$ \\
\hline EvER-ILD (NCT02990286) & $\begin{array}{l}\text { CTD-ILD or IPAF or idiopathic ILD, } \\
\text { plus NSIP based on HRCT or } \\
\text { histology, plus lack of response to } \\
\text { immunosuppressant therapy for } \\
\text { ILD }\end{array}$ & 122 & $\begin{array}{l}\text { Rituximab added to } \\
\text { MMF } \\
\text { (versus MMF alone) }\end{array}$ & $\begin{array}{l}\text { Change in FVC \% predicted at } \\
\text { week } 24 \text { (primary endpoint) } \\
\text { and change in DLco at week } 24 \\
\text { (secondary endpoint) }\end{array}$ \\
\hline RECITAL (NCT01862926) [97] & $\begin{array}{l}\text { Severe and/or progressive ILD asso- } \\
\text { ciated with SSc, idiopathic in- } \\
\text { flammatory myositis (including } \\
\text { anti-synthetase syndrome), or } \\
\text { MCTD }\end{array}$ & 116 & $\begin{array}{l}\text { Rituximab versus IV } \\
\text { CYC }\end{array}$ & $\begin{array}{l}\text { Changes in FVC (mL) at week } 24 \\
\text { (primary endpoint) and } 48 \\
\text { (secondary endpoint) }\end{array}$ \\
\hline APRIL (NCT03084419) & RA-ILD & 30 & Abatacept & Change in FVC over 28 weeks \\
\hline
\end{tabular}

${ }^{\text {a }}$ Patients receiving prednisone $\leq 10 \mathrm{mg} /$ day and/or stable therapy with mycophenolate (mofetil or sodium) or methotrexate ( $\geq 6$ months) were eligible for inclusion. Patients were not eligible if they had received azathioprine $\leq 8$ weeks, or CYC, cyclosporine, or rituximab $\leq 6$ months prior to randomization. Immunosuppressants were allowed during the trial in cases of clinically significant deterioration

${ }^{\mathrm{b}}$ Patients were not eligible if they had received azathioprine, CYC, MMF, tacrolimus, oral corticosteroids $>20 \mathrm{mg} /$ day, or a combination of oral corticosteroids, azathioprine, and N-acetylcysteine within 4 weeks; CYC within 8 weeks; or rituximab within 6 months prior to randomization. These drugs were allowed after 6 months of study treatment in case of worsening of ILD or autoimmune disease

${ }^{\mathrm{c}}$ Patients were not eligible if they had an introduction or dose modification of corticosteroids (except prednisone or equivalent maintained at $\leq 20 \mathrm{mg} /$ day) or any cytotoxic, immunosuppressive, or cytokine modulating or receptor antagonist agent for the management of pulmonary manifestations of RA $\leq 3$ months prior to screening

${ }^{\mathrm{d}}$ Patients were not eligible if they had received oral CYC, MMF, azathioprine, or other putative disease-modifying medications $\leq 12$ weeks prior to screening; had received $\geq 3$ intravenous doses of CYC, rituximab, or other injectable medication with putative disease-modifying activity $\leq 6$ months prior to screening; or had received prednisone (or equivalent) $>10 \mathrm{mg} /$ day $\leq 30$ days prior to their baseline visit

${ }^{\mathrm{e}}$ Patients were not eligible if they had received prednisone $>10 \mathrm{mg}$ /day within 2 weeks; had received azathioprine, hydroxychloroquine, colchizine, Dpenicillamine, and sulfasalazine within 8 weeks; or had received CYC, rituximab, tocilizumab, abatacept, leflunomide, tacrolimus, newer anti-arthritic treatments like tofacitinib and ciclosporine A, or potassium para-aminobenzoate within 6 months 
injuries at alveolar epithelial or microvascular endothelial sites, which lead to cell destruction and unregulated repair. Fibroblasts orchestrated to the sites of injury are activated to become myofibroblasts, which secrete excessive amounts of extracellular matrix (ECM), resulting in increased tissue stiffness, which in turn further activates and stimulates fibroblasts $[69,70]$. Macrophages and lymphocytes recruited to the site of injury release pro-fibrotic mediators, and vascular damage leads to the activation and degranulation of platelets, which release pro-fibrotic mediators. These mediators further promote fibroblast activation, driving a self-sustaining process of progressive fibrosis $[70,73,74]$. Coagulation pathways that are activated by tissue damage may also drive fibrosis $[75,76]$. As fibrosis progresses, the accumulation of ECM increases the diffusion distances between blood vessels and cells, reducing the oxygen supply to tissues [77]. Vascular alterations and reduced capillary density may also reduce oxygen supply [77]. In a self-sustaining loop, tissue hypoxia may stimulate further production of ECM proteins $[78,79]$. Several epigenetic modifications have also been implicated in the activation of fibroblasts in fibrosing lung diseases [80, 81].

The commonalities in the pathogenic mechanisms that drive fibrosis with different triggers suggest that drugs that slow disease progression in patients with IPF might also inhibit the progression of other ILDs. Nintedanib and pirfenidone reduce the rate of decline in lung function in patients with IPF $[82,83]$. The mechanism of action of pirfenidone remains unclear, but it has been shown to reduce the proliferation of fibroblasts and myofibroblasts and to inhibit ECM synthesis and deposition [84, 85]. Nintedanib has demonstrated anti-fibrotic, anti-inflammatory, and vascular remodelling effects in several animal models resembling aspects of fibrosing ILDs [72, 86-93]. In Fra2 mice, a model of the fibrotic and vascular manifestations of SSc, nintedanib reduced hydroxyproline levels and myofibroblast counts in the lung, as well as reducing the thickening of the walls of pulmonary arteries [90]. In transgenic SKG mice, a model resembling aspects of RA-ILD, nintedanib reduced hydroxyproline levels and $\alpha$-smooth muscle actin staining in the lungs [93].

The Phase III SENSCIS ${ }^{\circledR}$ trial assessed the efficacy and safety of nintedanib in 576 patients with SSc-ILD [94]. Nintedanib reduced the annual rate of decline in FVC versus placebo in a broad range of patients, including those with diffuse cutaneous SSc and limited cutaneous SSc and patients who were and were not taking mycophenolate at baseline. The safety profile of nintedanib was similar to that observed in patients with IPF, characterized mainly by mild or moderate gastrointestinal events, particularly diarrhea [94], and the gastrointestinal adverse event profile was similar in patients who were and were not taking mycophenolate [95]. Other large trials of anti-fibrotic therapies in patients with ILDs related to systemic autoimmune diseases are ongoing (Table 1). The INBUILD ${ }^{\circledR}$ trial (NCT02999178) is investigating the effects of nintedanib versus placebo in patients with progressive fibrosing ILDs other than IPF, including those associated with autoimmune diseases [96]. SLS III (NCT03221257) is studying the efficacy and safety of pirfenidone added to MMF versus MMF alone in patients with SSc-ILD, while the effects of pirfenidone versus placebo in patients with RA-ILD are being investigated in TRAIL I (NCT02808871). Based on their metabolism [98, 99], drug-drug interactions between anti-fibrotic therapies and immunosuppressant therapies are not expected, but further data are needed.

\section{Conclusions}

ILD is a major cause of morbidity and mortality in patients with systemic autoimmune diseases. Immunosuppressant therapy is the mainstay of therapy for these diseases, but there is very limited evidence to support its efficacy in treating ILD apart from SSc-ILD. Clinical and mechanistic similarities among progressive fibrosing ILDs suggest that drugs known to slow disease progression in patients with IPF may also slow the progression of ILD associated with systemic autoimmune diseases. In the SENSCIS trial, nintedanib reduced the annual rate of decline in FVC in a broad range of patients with SScILD, including those taking mycophenolate, suggesting that in future, the paradigm for treating autoimmune ILDs may shift to a combination of immunosuppressant and anti-fibrotic therapy.

Acknowledgments Medical writing assistance, supported financially by Boehringer Ingelheim, was provided by Elizabeth Ng and Wendy Morris of FleishmanHillard Fishburn, London, UK, during the preparation of this manuscript. The authors were fully responsible for all content and editorial decisions, were involved at all stages of development, and have approved the final version.

Data availability Not applicable to this article as no datasets were generated or analyzed.

\section{Compliance with ethical standards}

The manuscript does not contain clinical studies or patient data.

Conflict of interest Aryeh Fischer reports grants and personal fees from Boehringer Ingelheim and personal fees from Genentech-Roche, Pfizer, and Genentech. Jörg Distler has nothing to disclose. The authors have received no payment for this article.

Open Access This article is distributed under the terms of the Creative Commons Attribution 4.0 International License (http:// creativecommons.org/licenses/by/4.0/), which permits unrestricted use, distribution, and reproduction in any medium, provided you give appropriate credit to the original author(s) and the source, provide a link to the Creative Commons license, and indicate if changes were made. 


\section{References}

1. Steele R, Hudson M, Lo E et al (2012) Clinical decision rule to predict the presence of interstitial lung disease in systemic sclerosis. Arthritis Care Res 64:519-524

2. Bongartz T, Nannini C, Medina-Velasquez YF et al (2010) Incidence and mortality of interstitial lung disease in rheumatoid arthritis: a population-based study. Arthritis Rheum 62:1583-1591

3. Reiseter S, Gunnarsson R, Mogens Aaløkken T et al (2018) Progression and mortality of interstitial lung disease in mixed connective tissue disease: a long-term observational nationwide cohort study. Rheumatology (Oxford) 57:255-262

4. Marie I, Hachulla E, Chérin P et al (2002) Interstitial lung disease in polymyositis and dermatomyositis. Arthritis Rheum 47:614-622

5. Nannini C, Jebakumar AJ, Crowson CS et al (2013) Primary Sjögren's syndrome 1976-2005 and associated interstitial lung disease: a population-based study of incidence and mortality. BMJ Open 3:e003569

6. Gunnarsson R, Aaløkken TM, Molberg Ø et al (2012) Prevalence and severity of interstitial lung disease in mixed connective tissue disease: a nationwide, cross-sectional study. Ann Rheum Dis 71: 1966-1972

7. Winstone TA, Assayag D, Wilcox PG et al (2014) Predictors of mortality and progression in scleroderma-associated interstitial lung disease: a systematic review. Chest 146:422-436

8. Zamora-Legoff JA, Krause ML, Crowson CS et al (2017) Progressive decline of lung function in rheumatoid arthritisassociated interstitial lung disease. Arthritis Rheum 69:542-549

9. Wijsenbeek M, Kreuter M, Fischer A et al (2018) Non-IPF progressive fibrosing interstitial lung diseases: the patient journey. Poster presented at the American Thoracic Society (ATS) International Conference. Available at: https://ILDPosters2018.com/pdf/ATS PFILDs_Wijsenbeek.pdf. Accessed July 2019

10. Olson A, Hartmann N, Schlenker-Herceg R et al (2018) Prevalence of progressive fibrosing interstitial lung disease. Poster presented at European Respiratory Society international congress

11. Fischer A, du Bois R (2012) Interstitial lung disease in connective tissue disorders. Lancet 380:689-698

12. Cottin V, Thivolet-Bejui F, Reynaud-Gaubert M et al (2003) Interstitial lung disease in amyopathic dermatomyositis, dermatomyositis and polymyositis. Eur Respir J 22:245-250

13. Lee HK, Kim DS, Yoo B et al (2005) Histopathologic pattern and clinical features of rheumatoid arthritis-associated interstitial lung disease. Chest 127:2019-2027

14. Fischer A, Antoniou KM, Brown KK et al (2015) ERS/ATS task force on undifferentiated forms of CTD-ILD. An official European Respiratory Society/American Thoracic Society research statement: interstitial pneumonia with autoimmune features. Eur Respir J 46: 976-987

15. Collins BF, Spiekerman CF, Shaw MA et al (2017) Idiopathic interstitial pneumonia associated with autoantibodies: a large case series followed over 1 year. Chest 152:103-112

16. van den Hoogen F, Khanna D, Fransen J et al (2013) 2013 classification criteria for systemic sclerosis: an American College of Rheumatology/European League against Rheumatism collaborative initiative. Arthritis Rheum 65:2737-2747

17. Sánchez-Cano D, Ortego-Centeno N, Callejas JL et al (2018) Interstitial lung disease in systemic sclerosis: data from the Spanish scleroderma study group. Rheumatol Int 38:363-374

18. Dawson JK, Fewins HE, Desmond J et al (2001) Fibrosing alveolitis in patients with rheumatoid arthritis as assessed by high resolution computed tomography, chest radiography, and pulmonary function tests. Thorax 56:622-627
19. Koduri G, Norton S, Young A et al (2010) Interstitial lung disease has a poor prognosis in rheumatoid arthritis: results from an inception cohort. Rheumatology (Oxford) 49:1483-1489

20. Sparks JA, He X, Huang J et al (2019) Rheumatoid arthritis disease activity predicting incident clinically-apparent RA-associated interstitial lung disease: a prospective cohort study. Arthritis Rheumatol. https://doi.org/10.1002/art.40904 Epub ahead of print

21. Desai SR, Veeraraghavan S, Hansell DM et al (2004) CT features of lung disease in patients with systemic sclerosis: comparison with idiopathic pulmonary fibrosis and nonspecific interstitial pneumonia. Radiology 232:560-567

22. Bouros D, Wells AU, Nicholson AG et al (2002) Histopathologic subsets of fibrosing alveolitis in patients with systemic sclerosis and their relationship to outcome. Am J Respir Crit Care Med 165: $1581-1586$

23. Enomoto Y, Takemura T, Hagiwara E et al (2013) Prognostic factors in interstitial lung disease associated with primary Sjögren's syndrome: a retrospective analysis of 33 pathologically-proven cases. PLoS One 8:e73774

24. Douglas WW, Tazelaar HD, Hartman TE et al (2001) Polymyositisdermatomyositis-associated interstitial lung disease. Am J Respir Crit Care Med 164:1182-1185

25. Cobo-Ibáñez T, López-Longo FJ, Joven B et al (2019) Long-term pulmonary outcomes and mortality in idiopathic inflammatory myopathies associated with interstitial lung disease. Clin Rheumatol 38:803-815

26. Kelly CA, Saravanan V, Nisar M et al (2014) Rheumatoid arthritisrelated interstitial lung disease: associations, prognostic factors and physiological and radiological characteristics-a large multicentre UK study. Rheumatology (Oxford) 53:1676-1682

27. Launay D, Remy-Jardin M, Michon-Pasturel U et al (2006) High resolution computed tomography in fibrosing alveolitis associated with systemic sclerosis. J Rheumatol 33:1789-1801

28. Natalini JG, Swigris JJ, Morisset J et al (2017) Understanding the determinants of health-related quality of life in rheumatoid arthritisassociated interstitial lung disease. Respir Med 127:1-6

29. Jaeger VK, Distler O, Maurer B et al (2018) Functional disability and its predictors in systemic sclerosis: a study from the DeSScipher project within the EUSTAR group. Rheumatology (Oxford) 57:441-450

30. Kolb M, Vašáková M (2019) The natural history of progressive fibrosing interstitial lung diseases. Respir Res 20:57

31. Jaeger VK, Wirz EG, Allanore Y et al (2016) Incidences and risk factors of organ manifestations in the early course of systemic sclerosis: a longitudinal EUSTAR study. PLoS One 11:e0163894

32. Marie I, Hatron PY, Dominique S et al (2011) Short-term and longterm outcomes of interstitial lung disease in polymyositis and dermatomyositis: a series of 107 patients. Arthritis Rheum 63:34393447

33. Parambil JG, Myers JL, Lindell RM et al (2006) Interstitial lung disease in primary Sjögren syndrome. Chest 130:1489-1495

34. Yamakawa H, Hagiwara E, Kitamura H et al (2018) Predictive factors for the long-term deterioration of pulmonary function in interstitial lung disease associated with anti-aminoacyl-trna synthetase antibodies. Respiration 96:210-221

35. Elhai M, Meune C, Boubaya M et al (2017) Mapping and predicting mortality from systemic sclerosis. Ann Rheum Dis 76: 1897-1905

36. Goh NS, Desai SR, Veeraraghavan S et al (2008) Interstitial lung disease in systemic sclerosis: a simple staging system. Am J Respir Crit Care Med 177:1248-1254

37. Tyndall AJ, Bannert B, Vonk M et al (2010) Causes and risk factors for death in systemic sclerosis: a study from the EULAR Scleroderma Trials and Research (EUSTAR) database. Ann Rheum Dis 69:1809-1815 
38. Goh NS, Hoyles RK, Denton CP et al (2017) Short-term pulmonary function trends are predictive of mortality in interstitial lung disease associated with systemic sclerosis. Arthritis Rheum 69:1670-1678

39. Olson AL, Swigris JJ, Sprunger DB et al (2011) Rheumatoid arthritis-interstitial lung disease-associated mortality. Am J Respir Crit Care Med 183:372-378

40. Hyldgaard C, Hilberg O, Pedersen AB et al (2017) A populationbased cohort study of rheumatoid arthritis-associated interstitial lung disease: comorbidity and mortality. Ann Rheum Dis 76: 1700-1706

41. Solomon JJ, Chung JH, Cosgrove GP et al (2016) Predictors of mortality in rheumatoid arthritis-associated interstitial lung disease. Eur Respir J 47:588-596

42. Kim EJ, Elicker BM, Maldonado F et al (2010) Usual interstitial pneumonia in rheumatoid arthritis-associated interstitial lung disease. Eur Respir J 35:1322-1328

43. Assayag D, Lubin M, Lee JS et al (2014) Predictors of mortality in rheumatoid arthritis-related interstitial lung disease. Respirology 19:493-500

44. Fu Q, Wang L, Li L et al (2019) Risk factors for progression and prognosis of rheumatoid arthritis-associated interstitial lung disease: single center study with a large sample of Chinese population. Clin Rheumatol 38:1109-1116

45. Chartrand S, Fischer A (2015) Assessment and management of connective tissue disease associated interstitial lung disease. Sarcoidosis Vasc Diffuse Lung Dis 32:2-21

46. Khanna D, Strek M, Southern B et al (2018) Expert consensus on the screening, treatment, and management of patients with systemic sclerosis-interstitial lung disease, and the potential role of antifibrotics in a treatment paradigm for systemic sclerosis-interstitial lung disease: a Delphi consensus study. Arthritis Rheumatol 70(suppl 10):abstract no 1717. Available from https://acrabstracts. org/abstract. Accessed July 2019

47. Fischer A, Richeldi L (2014) Cross-disciplinary collaboration in connective tissue disease-related lung disease. Semin Respir Crit Care Med 35:159-165

48. Hoyles RK, Ellis RW, Wellsbury J et al (2006) A multicenter, prospective, randomized, double-blind, placebo-controlled trial of corticosteroids and intravenous cyclophosphamide followed by oral azathioprine for the treatment of pulmonary fibrosis in scleroderma. Arthritis Rheum 54:3962-3970

49. Tashkin DP, Elashoff R, Clements PJ et al (2006) Cyclophosphamide versus placebo in scleroderma lung disease. N Engl J Med 354:2655-2666

50. Kowal-Bielecka O, Landewé R, Avouac J et al (2009) EULAR recommendations for the treatment of systemic sclerosis: a report from the EULAR Scleroderma Trials and Research group (EUSTAR). Ann Rheum Dis 68:620-628

51. Kowal-Bielecka O, Fransen J, Avouac J et al (2017) Update of EULAR recommendations for the treatment of systemic sclerosis. Ann Rheum Dis 76:1327-1339

52. Tashkin DP, Roth MD, Clements PJ et al (2016) Mycophenolate mofetil versus oral cyclophosphamide in scleroderma-related interstitial lung disease (SLS II): a randomised controlled, double-blind, parallel group trial. Lancet Respir Med 4:708-719

53. Fernández-Codina A, Walker KM, Pope JE et al (2018) Treatment algorithms for systemic sclerosis according to experts. Arthritis Rheum 70:1820-1828

54. Hoffmann-Vold A-M, Maher TM, Philpot EE et al (2019) Evidence-based consensus recommendations for the identification and management of interstitial lung disease in systemic sclerosis. Ann Rheum Dis 78(Suppl 2):A104

55. Paone C, Chiarolanza I, Cuomo G et al (2007) Twelve-month azathioprine as maintenance therapy in early diffuse systemic sclerosis patients treated for 1-year with low dose cyclophosphamide pulse therapy. Clin Exp Rheumatol 25:613-616
56. Bérezné A, Ranque B, Valeyre D et al (2008) Therapeutic strategy combining intravenous cyclophosphamide followed by oral azathioprine to treat worsening interstitial lung disease associated with systemic sclerosis: a retrospective multicenter open-label study. J Rheumatol 35:1064-1072

57. Daoussis D, Liossis SN, Tsamandas AC et al (2010) Experience with rituximab in scleroderma: results from a 1-year, proof-ofprinciple study. Rheumatology (Oxford) 49:271-280

58. Sircar G, Goswami RP, Sircar D et al (2018) Intravenous cyclophosphamide vs rituximab for the treatment of early diffuse scleroderma lung disease: open label, randomized, controlled trial. Rheumatology (Oxford) 57:2106-2113

59. Fischer A, Brown KK, du Bois RM et al (2013) Mycophenolate mofetil improves lung function in connective tissue diseaseassociated interstitial lung disease. J Rheumatol 40:640-646

60. Oldham JM, Lee C, Valenzi E et al (2016) Azathioprine response in patients with fibrotic connective tissue disease-associated interstitial lung disease. Respir Med 121:117-122

61. Kelly C, Palmer E, Gordon J et al (2014) Pulsed cyclophosphamide in the treatment of rheumatoid arthritis-related interstitial lung disease (RA-ILD). Ann Rheum Dis 2014(73):74

62. Md Yusof MY, Kabia A, Darby M et al (2017) Effect of rituximab on the progression of rheumatoid arthritis-related interstitial lung disease: 10 years' experience at a single centre. Rheumatology (Oxford) 56:1348-1357

63. Fernández-Díaz C, Loricera J, Castañeda S et al (2018) Abatacept in patients with rheumatoid arthritis and interstitial lung disease: a national multicenter study of 63 patients. Semin Arthritis Rheum 48:22-27

64. Yamasaki Y, Yamada H, Yamasaki M et al (2007) Intravenous cyclophosphamide therapy for progressive interstitial pneumonia in patients with polymyositis/dermatomyositis. Rheumatology (Oxford) 46:124-130

65. Lepri G, Avouac J, Airò P et al (2016) Effects of rituximab in connective tissue disorders related interstitial lung disease. Clin Exp Rheumatol 34:181-185

66. Doyle TJ, Dhillon N, Madan R et al (2018) Rituximab in the treatment of interstitial lung disease associated with antisynthetase syndrome: a multicenter retrospective case review. J Rheumatol 45: $841-850$

67. Roubille C, Haraoui B (2014) Interstitial lung diseases induced or exacerbated by DMARDS and biologic agents in rheumatoid arthritis: a systematic literature review. Semin Arthritis Rheum 43: 613-626

68. Rojas-Serrano J, Herrera-Bringas D, Pérez-Román DI et al (2017) Rheumatoid arthritis-related interstitial lung disease (RA-ILD): methotrexate and the severity of lung disease are associated to prognosis. Clin Rheumatol 36:1493-1500

69. Strieter RM, Mehrad B (2009) New mechanisms of pulmonary fibrosis. Chest 136:1364-1370

70. Bagnato G, Harari S (2015) Cellular interactions in the pathogenesis of interstitial lung diseases. Eur Respir Rev 24:102-114

71. Wollin L, Distler JHW, Denton CP et al (2019) Rationale for the evaluation of nintedanib as a treatment for systemic sclerosisassociated interstitial lung disease. J Scleroderma Relat Disord. https://doi.org/10.1177/2397198319841842 Epub ahead of print

72. Wollin L, Distler JHW, Redente EF et al (2019) Potential of nintedanib in treatment of progressive fibrosing interstitial lung diseases. Eur Respir J. https://doi.org/10.1183/13993003.001612019 Epub ahead of print

73. Ntelis K, Solomou EE, Sakkas L (2017) The role of platelets in autoimmunity, vasculopathy, and fibrosis: implications for systemic sclerosis. Semin Arthritis Rheum 47:409-417

74. Scherlinger M, Guillotin V, Truchetet ME et al (2018) Systemic lupus erythematosus and systemic sclerosis: all roads lead to platelets. Autoimmun Rev 17:625-635 
75. Cerinic MM, Valentini G, Sorano GG et al (2003) Blood coagulation, fibrinolysis, and markers of endothelial dysfunction in systemic sclerosis. Semin Arthritis Rheum 32:285-295

76. Chrysanthopoulou A, Mitroulis I, Kambas K et al (2011) Tissue factor-thrombin signaling enhances the fibrotic activity of myofibroblasts in systemic sclerosis through up-regulation of endothelin receptor A. Arthritis Rheum 63:3586-3597

77. Beyer C, Schett G, Gay S et al (2009) Hypoxia in the pathogenesis of systemic sclerosis. Arthritis Res Ther 11:220

78. Distler JH, Jüngel A, Pileckyte M et al (2007) Hypoxia-induced increase in the production of extracellular matrix proteins in systemic sclerosis. Arthritis Rheum 56:4203-4215

79. Karakiulakis G, Papakonstantinou E, Aletras AJ et al (2007) Cell type-specific effect of hypoxia and platelet-derived growth factor$\mathrm{BB}$ on extracellular matrix turnover and its consequences for lung remodeling. J Biol Chem 282:908-915

80. Luo Y, Wang Y, Shu Y et al (2015) Epigenetic mechanisms: an emerging role in pathogenesis and its therapeutic potential in systemic sclerosis. Int J Biochem Cell Biol 67:92-100

81. Yang IV, Schwartz DA (2015) Epigenetics of idiopathic pulmonary fibrosis. Transl Res 165:48-60

82. Richeldi L, du Bois RM, Raghu G et al (2014) Efficacy and safety of nintedanib in idiopathic pulmonary fibrosis. N Engl J Med 370: 2071-2082

83. King TE Jr, Bradford WZ, Castro-Bernardini S et al (2014) A phase 3 trial of pirfenidone in patients with idiopathic pulmonary fibrosis. N Engl J Med 370:2083-2092

84. Schaefer CJ, Ruhrmund DW, Pan L et al (2011) Antifibrotic activities of pirfenidone in animal models. Eur Respir Rev 20:85-97

85. Conte E, Gili E, Fagone E et al (2014) Effect of pirfenidone on proliferation, TGF- $\beta$-induced myofibroblast differentiation and fibrogenic activity of primary human lung fibroblasts. Eur J Pharm Sci 58:13-19

86. Hostettler KE, Zhong J, Papakonstantinou E et al (2014) Antifibrotic effects of nintedanib in lung fibroblasts derived from patients with idiopathic pulmonary fibrosis. Respir Res 15:157

87. Wollin L, Maillet I, Quesniaux V et al (2014) Antifibrotic and antiinflammatory activity of the tyrosine kinase inhibitor nintedanib in experimental models of lung fibrosis. J Pharmacol Exp Ther 349: 209-220

88. Wollin L, Wex E, Pautsch A et al (2015) Mode of action of nintedanib in the treatment of idiopathic pulmonary fibrosis. Eur Respir J 45:1434-1445
89. Huang J, Beyer C, Palumbo-Zerr K et al (2016) Nintedanib inhibits fibroblast activation and ameliorates fibrosis in preclinical models of systemic sclerosis. Ann Rheum Dis 75:883-890

90. Huang J, Maier C, Zhang Y et al (2017) Nintedanib inhibits macrophage activation and ameliorates vascular and fibrotic manifestations in the Fra2 mouse model of systemic sclerosis. Ann Rheum Dis 76:1941-1948

91. Ackermann M, Kim YO, Wagner WL et al (2017) Effects of nintedanib on the microvascular architecture in a lung fibrosis model. Angiogenesis 20:359-372

92. Lee HY, Hur J, Kim IK et al (2017) Effect of nintedanib on airway inflammation and remodeling in a murine chronic asthma model. Exp Lung Res 43:187-196

93. Redente EF, Aquilaret MA, Black BP et al (2018) Nintedanib reduces pulmonary fibrosis in a model of rheumatoid arthritisassociated interstitial lung disease. Am J Phys Lung Cell Mol Phys 314:L998-L1009

94. Distler O, Highland KB, Gahlemann M et al (2019) Nintedanib for systemic sclerosis-associated interstitial lung disease. N Engl J Med 380:2518-2528

95. Maher TM, Highland KB, Gahlemann M et al (2019) Gastrointestinal adverse events in patients with systemic sclerosis-associated interstitial lung disease (SSc-ILD) treated with nintedanib: data from the SENSCIS trial. Ann Rheum Dis 78(Suppl.2):A831

96. Flaherty KR, Brown KK, Well AU et al (2017) Design of the PFILD trial: a double-blind, randomised, placebo-controlled phase III trial of nintedanib in patients with progressive fibrosing interstitial lung disease. BMJ Open Respir Res 4:e000212

97. Saunders P, Tsipouri V, Keir GJ et al (2017) Rituximab versus cyclophosphamide for the treatment of connective tissue diseaseassociated interstitial lung disease (RECITAL): study protocol for a randomised controlled trial. Trials 18:275

98. Boehringer Ingelheim Pharmaceuticals, Inc. OFEV® (nintedanib) prescribing information (2018). Available at: https://docs. boehringer-ingelheim.com/Prescribing\%20Information/PIs/Ofev/ ofev.pdf Accessed July 2019

99. Genentech, Inc. ESBRIET ${ }^{\circledR}$ (pirfenidone) prescribing information (2017). Available at: https://www.gene.com/download/pdf/esbriet prescribing.pdf. Accessed July 2019

Publisher's note Springer Nature remains neutral with regard to jurisdictional claims in published maps and institutional affiliations. 